\title{
Avifauna and urban encroachment in time and space
}

Laura RAYNER, Karen IKIN, Maldwyn J. EVANS, Philip GIBBONS, David B. LINDENMAYER and Adrian D. MANNING

\begin{abstract}
Urban expansion significantly alters fringe environments often with undesirable impacts on biodiversity. Consequently, there is a need to define clear conservation objectives for areas subject to urban encroachment. Urban fringe development is a highly dynamic process, both spatially and temporally, but few studies are equipped to examine its temporal effects on biota. We aimed to explore the impacts of urban encroachment on avifauna through space and time. We used records from an extensive 14-year monitoring program undertaken in temperate woodland. We fitted hierarchical generalised linear models to assess individual species responses to the distance from monitoring sites to the urban boundary, and the temporal rate of change in this distance through time. We used factorial analysis on mixed data to examine trait group responses to these predictors.

Our results indicated that the occurrence of approximately half of the study region's avifauna is strongly linked to the proximity of their habitat to the urban fringe, but that the impact of urban fringe development on the occurrence of some species changed through time. We identified several species of conservation concern that respond negatively to large annual increases in urban fringe development, irrespective of its proximity to suitable habitat. Species responses to urban proximity were linked to life history traits, with small, migratory, woodland-dependent species that rely on midand upper-canopy structures, clearly disadvantaged by urban environments. Our findings demonstrate the breadth of species responses to urban encroachment over much larger distances than is typically investigated in urban ecological studies. We identify guilds vulnerable to the impacts of urban fringe development, and therefore in need of ecologically sensitive urban design. We argue that future urban expansion toward important fringe habitats will need to be planned strategically through space and time.
\end{abstract}




\section{INTRODUCTION}

Urban areas occupy a relatively small proportion of terrestrial land (Grimm et al., 2008), but impact disproportionately on biologically productive landscapes (Luck, 2007). Consequently, highly populated environments and biodiversity hotspots show strong spatial congruence at broad scales (Güneralp \& Seto, 2013). In these species-rich environments, human population growth exceeds that of global background levels (Cincotta et al., 2000; Seto et al., 2012). Urban expansion is spatially concentrated at the edge of major urban centres (Fisher, 2003; Robinson et al., 2005), significantly and disproportionately altering fringe ecosystems (Radeloff et al., 2005) often with undesirable impacts on biodiversity (Marzluff et al. 2001; Pautasso, 2007).

Urban fringe development threatens biodiversity through habitat loss (Foley et al., 2005), fragmentation (Crossman et al., 2007) and the introduction of invasive species (Marzluff \& Ewing, 2001; Forys \& Allen, 2005). If persistent, these threats can ultimately lead to biotic homogenization (McKinney, 2006) and species population declines (Aronson et al., 2014) in affected environments. Urban encroachment into rural or wild lands also can undermine the effectiveness of nearby protected areas to abate such threats (Radeloff et al., 2010) and to safeguard species populations in perpetuity (Rayner et al., 2014). However, evidence also exists for species that are promoted by urbanisation (e.g. Wania et al., 2006). This is particularly the case where important or rare habitats occur within urban landscapes (Sorace \& Gustin, 2010).

Conflicting data on the impacts of urban fringe development on biodiversity means it is difficult to define clear conservation objectives for peri-urban environments (Turner et al., 2004). This is pertinent to Australia, where over $50 \%$ of nationally-listed threatened species occur in vulnerable urban fringe habitats (Bekessy et al., 2012). In response to this challenge, many researchers have examined the effects of urbanisation on neighbouring ecological communities, primarily using sites located along urban-rural gradients (reviewed in McKinney, 2002). However, few studies have explored the ecological effects of urbanisation through time (Chace \& Walsh, 2006; Garden et al., 2006; Chamberlain et al., 2009; Luck \& Smallbone, 2010).

Understanding the temporal patterns in responses of biota to urban fringe development is important because the process of land-use change is dynamic, both spatially and temporally (Figure 1), and because faunal communities are assumed to change with ongoing development (Scott, 1993). Therefore, an important consideration when evaluating the effects of urban fringe development on neighbouring species populations may not only be the extent and proximity of development, but the rate of land-use change.

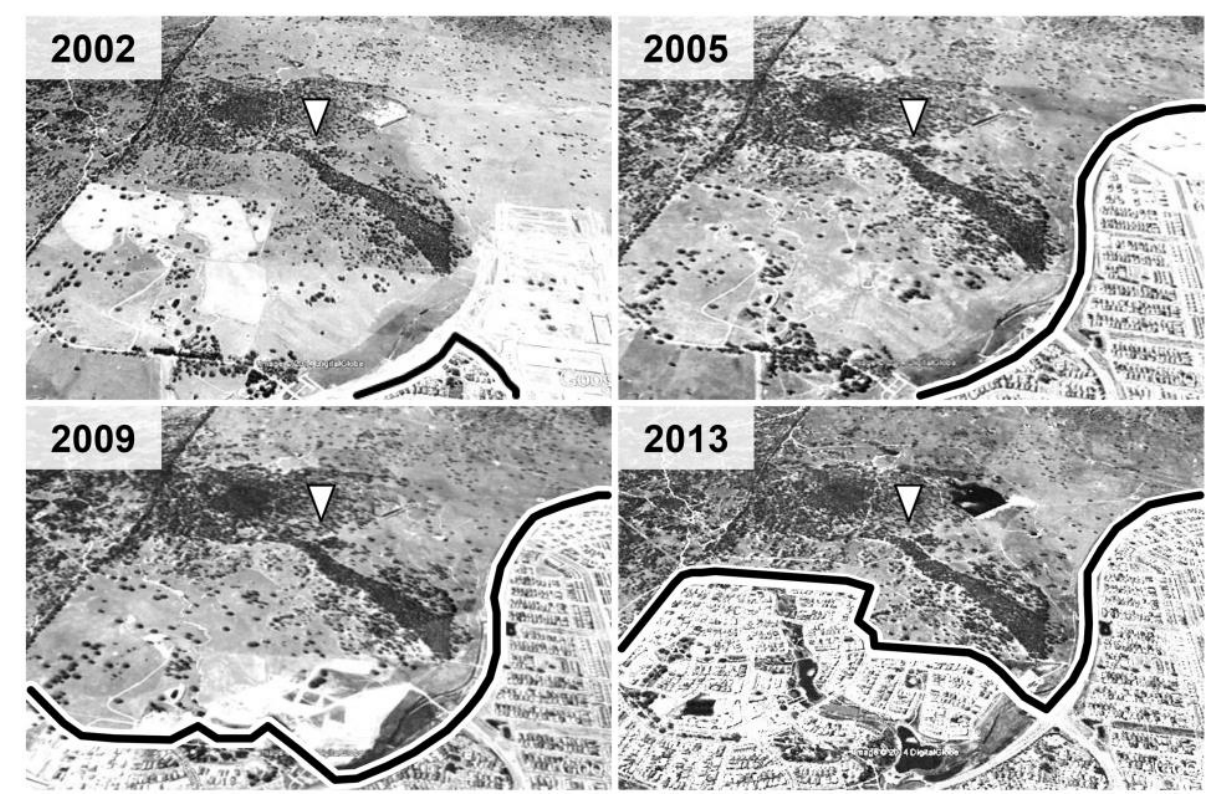

Figure 1. Example of the spatio-temporal change associated with urban fringe development in North Canberra, Australia. The urban boundary is indicated by the bold black line, with development encroaching into an endangered ecological community found in the study area (box-gum grassy woodland arrow) over a period of 12 years. Image source: Google Earth. 
In this study, we used records from a 14-year biodiversity monitoring program to explore the impacts of urban fringe development on a vulnerable assemblage of species: Australian temperate woodland birds. Our systematic survey design enabled us to examine the response of birds to both the spatial extent and temporal rate of urban fringe development (Figure 2) and test two key hypotheses:

\section{Hypothesis 1: The proximity of urban development will influence observed patterns of bird} occurrence in neighbouring woodland habitats. Many short-term studies have found distance to the urban boundary to be a driver of species abundance, occurrence and community structure (Brearley et al., 2010; Dallimer et al., 2012; Ikin et al., 2013), and that the tolerance of species to urban development is often linked to life history traits and resource use (Sol et al., 2014). For example, species requiring more complex environments (e.g. specialist species, small-bodied species) may be disadvantaged by the simplified structure of urban systems and may present as "urban avoiders" (sensu Blair, 1996). We postulated that the incidence and abundance of urban avoiders would increase with increasing distance from the urban fringe, and that the converse would be found for "urban exploiters" which favour urban zones (sensu Blair, 1996; Figure 2b).

Hypothesis 2: The negative impact of urbanisation on urban-sensitive species will be greater in areas of rapid encroachment than in areas of static or gradual change. Urban fringe development significantly modifies existing habitats (Grimm et al., 2008) with considerable levels of disturbance during the construction of human infrastructure. Human-induced disturbance significantly reduces bird densities and adversely affects foraging and breeding behaviour (Burton et al., 2002; Reijnen \& Foppen, 2006). We assumed that the larger the annual change in urban extent, the more pronounced the effects of disturbance would be, because more of the existing habitat is altered with little time for species to adapt.

Correspondingly, we postulated that the incidence of all species, but especially urban avoiders, would decrease with larger annual changes in urban proximity due to displacement effects (e.g. Pearce-Higgins et al., 2012; Figure 2c). However, over longer periods, we expected urban exploiters to respond positively to large changes in urban extent because the process of urban encroachment creates favourable habitat (post-disturbance) that will continue to be inhospitable to urban avoiders.

a

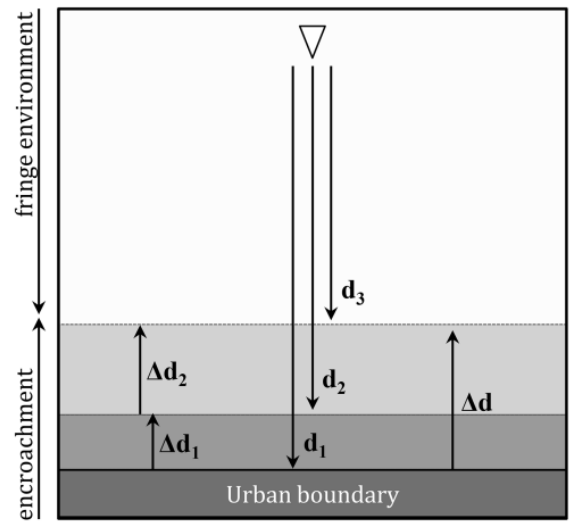

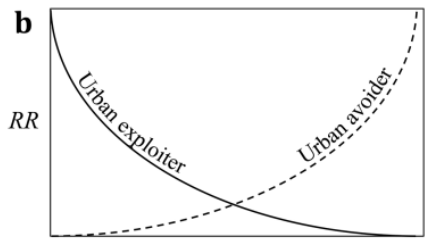

d

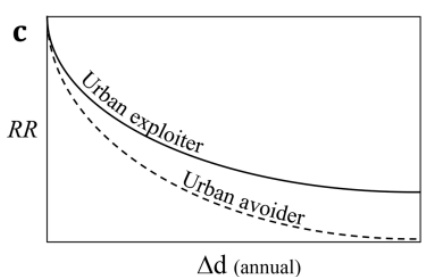

Figure 2. Conceptual model showing (a) the measures of urban encroachment used in this study, where: $\mathbf{d}$ is the distance from a permanent field monitoring site (arrow) to the urban boundary recorded at annual time steps $(1,2,3)$; and $\boldsymbol{\Delta} \mathbf{d}$ is the distance that the urban boundary has moved in time, recorded at annual time steps $(1,2)$ and over the full period of observation $\left(d_{1}-d_{n}\right)$. The hypothesized relationships between species reporting rate 'RR' (the proportion of surveys in which a species was recorded out of the total number of surveys conducted at a site in a given year) and our measures of urban encroachment are shown in figure panels (b) and (c). 
Our aim in testing these two hypotheses was to determine whether the rate of urban change had a distinct and significant effect on species inhabiting urban fringe ecosystems above that of spatial proximity alone. To our collective knowledge, this effect has not been previously examined with empirical field data.

\section{METHODS}

\section{Study region}

Our study area comprised a $20 \times 40 \mathrm{~km}$ area (bounded by $-35.1^{\circ}, 149.3^{\circ}$ and $-35.6^{\circ}, 148.9^{\circ}$ ) in the sub-humid region of the Australian Capital Territory, south-eastern Australia (Figure 3). The city of Canberra covers $\sim 800 \mathrm{~km}^{2}$ and contains a population of $\sim 380,000$ people (ABS, 2013). Population density in 2013 was 162 people $\mathrm{km}^{-2}$, but is variable across the Territory (ABS, 2013). Strongest population growth has occurred in the northern fringe suburbs of Canberra, shifting the centre of population north by $1.5 \mathrm{~km}$ over the last decade. In areas adjacent to our study sites, population density ranged from $0.44-14.54$ residents per hectare of urban area (mean $=8.63$, median $=10.28$ ). Residential density in these areas ranged from $0.28-6.58$ dwellings per hectare of urban area (mean $=3.48$, median $=3.70$ ). All new developments (areas measured as encroachment in this study) were uniformly higher in residential density, ranging from 3.89-6.58 dwellings per hectare of urban area ( mean $=4.95$, median $=4.64)$.

The dominant vegetation type in peri-urban zones of the study area was temperate eucalypt woodland. These woodlands once covered vast areas of the Australian continent, but have been heavily cleared since European settlement in the mid-1800s (Lindenmayer et al., 2010). Some large intact remnants of critically endangered box-gum grassy woodland remain in the study area (ACT, 2011), but most have been perturbed by grazing, altered fire regimes, and invasion by weeds and feral animals. Urbanisation presents ongoing threats to woodland extent in the region and significant challenges for protecting the ecological integrity of remnants on the urban fringe (Ikin et al., 2014; Rayner et al., 2014).

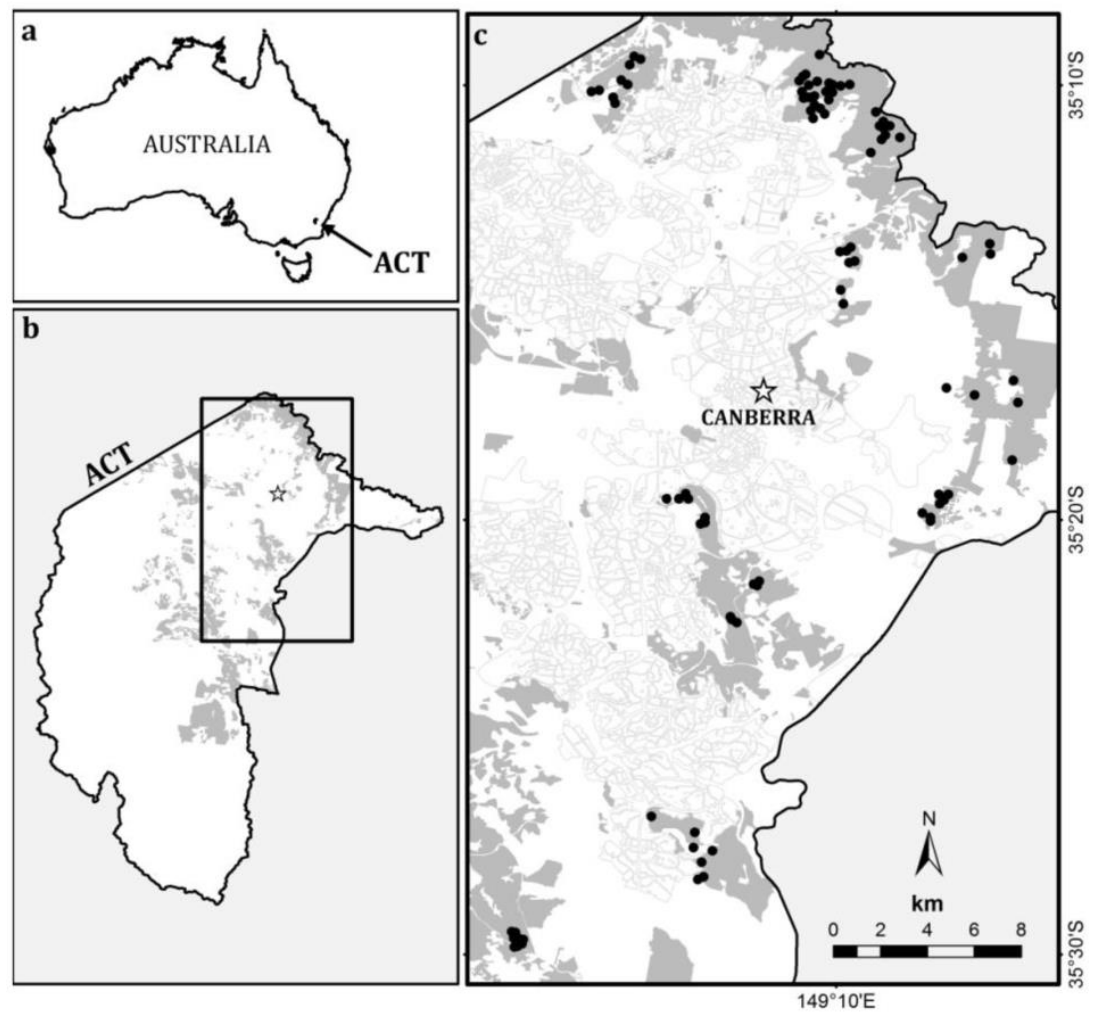

Figure 3. (a) Location of the Australian Capital Territory (ACT) within Australia, (b) distribution of woodland extent across the ACT (dark grey), and (c) the study area with location of sites (black circles) nested within 10 broader geographic locations situated in woodland remnants (dark grey) and the urban area (grey lines) including the location of the capital city, Canberra (star). 


\section{Bird data}

We sourced records of bird occurrence and abundance from a long-term woodland bird monitoring project undertaken by the Canberra Ornithologists Group. We used data from 92 permanent field sites nested within 10 broader survey locations (Figure 3). Sites were at least $100 \mathrm{~m}$ apart, ranging from a minimum of $105 \mathrm{~m}$ to a maximum of $2,473 \mathrm{~m}($ mean $=357 \mathrm{~m})$. All sites were located in temperate grassy woodland $(n=86)$ or dry forest contiguous with temperate grassy woodland $(n=6)$ for the duration of the study (i.e. no sites were consumed by urban development). Sites were surveyed every year for 14 years from 1999 to 2012. Surveys were 10-minute point-counts conducted seasonally (four surveys/site/year) with no changes to survey protocol and little appreciable variation in effort. During surveys, experienced observers counted all birds seen or heard within a $50 \mathrm{~m}$ radius. Detailed site descriptions and further information on bird survey protocols can be found in Bounds et al. (2010). Only species occurring in $>1 \%$ of surveys were included in formal analysis.

\section{Urban data}

Spatio-temporal data on the changing extent of urban Canberra were sourced from the Australian Capital Territory Government for the period 1999 to 2010. For our purposes, change in urban extent was recorded at the commencement of urban development. This included areas cleared of native vegetation for the construction of human infrastructure. From these data, we identified the location of the urban boundary at annual time steps. Geographic Information System (GIS) Software was used to calculate Euclidean distances from each of the 92 survey sites to the nearest point along the urban boundary corresponding with each year of bird survey data. Three metrics were calculated from these data for analysis (Figure 2a): Urban Distance (the distance from each site to the urban boundary for a given year), Urban Annual Change (the annual incremental change in Urban Distance through time, e.g. Urban Annual Change $2005=$ Urban Distance $_{2005}-$ Urban Distance $_{2004}$ ), and Urban Long-term Change (the total change in Urban Distance over the period 1999-2010.

\section{Statistical analysis}

We fitted hierarchical generalised linear mixed models (HGLM) to examine the separate effects of our three urbanisation metrics on individual species reporting rates and abundances. Reporting rates are defined as the proportion of surveys in which a species was recorded out of the total number of surveys conducted at a site in a given year. This response variable provides a measure of change in species site occurrences, accounting for small variations in survey effort directly. For each year, we also pooled multiple visits to a given site to calculate annual abundances for each species. We assumed quasi-binomial distributions for models using reporting rate, and Poisson distributions for models using relative abundance. We standardised all predictor variables prior to modelling. We modelled the variables Urban Distance and Urban Annual Change together (i.e. in the same model) to examine the independent effects of these predictors. For our investigation of long-term change, we related reporting rates and relative abundances calculated for the last two years of the dataset (2011/2012) to the total change in the urban boundary recorded between 1999 and 2010. We also provide long-term trend estimates based on simple linear models of species abundances to assist ecological inference of long-term encroachment effects. For all models, we accounted for spatial and temporal dependence in the data that resulted from location-, site-and year-specific variations in occurrence and abundance by including these factors as random effects. We assumed a betadistribution with a logit-link function for the random component in binomial models, and a gammadistribution with a log-link function for the random component in Poisson models. We fitted HGLMs in GenStat $15^{\text {th }}$ Edition statistical software package (VSN International Ltd).

We used Factorial Analysis on Mixed Data (FAMD) to examine the effect of Urban Distance and Urban Annual Change on functional trait groups. FAMD is a principal component method that explores similarities among trait groups in terms of their responses to environmental predictors. We included only those species that showed significant responses to either Urban Distance or Urban Annual Change in FAMD, analysing each predictor separately. Prior to analysis, we assigned each bird species to functional trait groups based on life-history attributes. These groups included habitat 
specialisation (woodland specialist, woodland generalist), mobility (sedentary, migratory, dispersive), body size (small, intermediate, large), and nesting substrate (hollow, understorey, arboreal, opportunistic). We provide details of trait assignment for individual species, including sources of information for classification in Supporting Information (see Appendix S1). We applied FAMD in the $\mathrm{R}$ statistical program (R Development Core Team) using the FactoMineR software package (Husson et al., 2014).

\section{RESULTS}

A total of 4,750 surveys was undertaken at the 92 permanent field monitoring sites between 1999 and 2012. We analysed data for 59 species that occurred in $>1 \%$ of surveys (Appendix S1). We excluded waterbirds from our analysis because their primary habitat is underrepresented in the dataset. The distance from survey sites to the urban boundary ranged from 16 to 5,363 metres between 1999 and 2010. The distance of urban encroachment ranged from 0 to 1,052 metres annually, and from 0 to 2,330 metres between 1999 and 2010 .

\section{Hypothesis 1: Effects of urban proximity}

\section{Individual species responses}

We identified 32 species whose reporting rates or abundances were significantly related to Urban Distance (Table 1). Responses were mixed with 15 species increasing (hereafter urban exploiters) and 17 species decreasing (hereafter urban avoiders) with urban proximity. The distance over which species were affected by urbanisation also varied (Figure 4a-d). For example, the Common Myna responded strongly within $1 \mathrm{~km}$ of development (e.g. Common Myna, Figure 4a), while the Red Wattlebird showed an urban response that extended up to $5 \mathrm{~km}$ away (Figure $4 \mathrm{~b}$ ). Only two exotic bird species were recorded during surveys (the Common Myna and Common Starling) and both showed significantly higher reporting rates proximal to the urban boundary. We found no observable effects of Urban Distance on the reporting rates or abundances of the remaining 27 bird species.

\section{Trait-based responses}

Dimensions one and two of our FAMD explained $45 \%$ of variability in trait-based responses to Urban Distance. We found a clear pattern in the response of trait groups along an urban proximity gradient (Dimension 1, Figure 5). Sites located nearest to the urban boundary supported larger-bodied species not strictly dependent on woodland habitats and opportunistic in their nesting requirements. In contrast, sites located at increasing distances from the urban boundary supported more smallerbodied, woodland-dependent birds that rely on mid- and upper-canopy structure for nesting. Hollowdependent species (also known as 'cavity nesters') showed a stronger association with sites located near to the urban boundary, as did sedentary species. Migratory and dispersive species were more likely to be observed on sites at increasing distances from the urban fringe. 
Table 1. Relationships between Urban Distance and species (a) reporting rates and (b) relative abundances. Positive estimates represent increasing reporting rate/abundance with increasing distance from the urban boundary. Only species showing a significant response to urban distance $(\alpha=0.05)$ are listed. Exotic species are denoted by an asterisk $(*)$. Scientific names for species are provided in Appendix S1.

\begin{tabular}{|c|c|c|c|c|c|c|c|c|c|}
\hline \multirow{2}{*}{ Response } & \multirow{2}{*}{ Species } & \multicolumn{4}{|c|}{ (a) Reporting rate } & \multicolumn{4}{|c|}{ (b) Relative abundance } \\
\hline & & Est. & SE & Wald & $\mathbf{P}$ & Est. & SE & Wald & $\mathbf{P}$ \\
\hline \multirow[t]{15}{*}{ Urban exploiters } & Australian King-Parrot & -2.656 & 0.658 & 16.29 & $<0.001$ & -2.724 & 0.595 & 20.98 & $<0.001$ \\
\hline & Brown Treecreeper & & & & & -3.698 & 0.824 & 20.16 & $<0.001$ \\
\hline & Common Myna* & -2.160 & 0.429 & 25.40 & $<0.001$ & & & & \\
\hline & Red-rumped Parrot & -1.565 & 0.444 & 12.42 & $<0.001$ & -4.006 & 0.738 & 29.46 & $<0.001$ \\
\hline & Welcome Swallow & -1.248 & 0.205 & 37.03 & $<0.001$ & & & & \\
\hline & Common Starling* & -0.769 & 0.162 & 22.55 & $<0.001$ & & & & \\
\hline & Crested Pigeon & -0.686 & 0.249 & 7.62 & 0.006 & -0.852 & 0.252 & 11.39 & $<0.001$ \\
\hline & Striated Pardalote & -0.317 & 0.112 & 8.10 & 0.004 & -0.256 & 0.086 & 8.82 & 0.003 \\
\hline & Eastern Rosella & -0.324 & 0.131 & 6.18 & 0.013 & -0.281 & 0.097 & 8.35 & 0.004 \\
\hline & Crimson Rosella & -0.188 & 0.073 & 6.73 & 0.009 & & & & \\
\hline & Grey Butcherbird & -0.443 & 0.142 & 9.74 & 0.002 & & & & \\
\hline & Red Wattlebird & -0.286 & 0.132 & 4.70 & 0.030 & -0.477 & 0.122 & 15.35 & $<0.001$ \\
\hline & Silvereye & -0.392 & 0.182 & 4.66 & 0.031 & & & & \\
\hline & Australian Raven & -0.289 & 0.142 & 4.15 & 0.042 & & & & \\
\hline & Mistletoebird & -0.278 & 0.137 & 4.12 & 0.042 & & & & \\
\hline \multirow[t]{17}{*}{ Urban avoiders } & Sacred Kingfisher & 1.310 & 0.247 & 28.04 & $<0.001$ & & & & \\
\hline & Superb Fairy-wren & 0.958 & 0.179 & 28.51 & $<0.001$ & & & & \\
\hline & Dusky Woodswallow & 0.874 & 0.257 & 11.56 & $<0.001$ & & & & \\
\hline & White-plumed Honeyeater & 0.757 & 0.218 & 12.02 & $<0.001$ & 0.579 & 0.232 & 6.21 & 0.013 \\
\hline & Common Bronzewing & 0.509 & 0.163 & 9.80 & 0.002 & & & & \\
\hline & Noisy Miner & 0.498 & 0.171 & 8.45 & 0.004 & & & & \\
\hline & Western Gerygone & 0.478 & 0.124 & 14.81 & $<0.001$ & & & & \\
\hline & Willie Wagtail & 0.476 & 0.165 & 8.34 & 0.004 & & & & \\
\hline & Scarlet Robin & 0.412 & 0.123 & 11.25 & $<0.001$ & 0.422 & 0.117 & 13.12 & $<0.001$ \\
\hline & Brown Treecreeper & 0.371 & 0.071 & 27.47 & $<0.001$ & & & & \\
\hline & Striated Thornbill & 0.344 & 0.100 & 11.76 & $<0.001$ & & & & \\
\hline & Tree Martin & 0.317 & 0.064 & 24.43 & $<0.001$ & & & & \\
\hline & Brown-headed Honeyeater & & & & & 0.432 & 0.158 & 7.51 & 0.006 \\
\hline & Rufous Whistler & 0.239 & 0.104 & 5.29 & 0.022 & & & & \\
\hline & Golden Whistler & 0.230 & 0.115 & 3.97 & 0.046 & & & & \\
\hline & Mistletoebird & & & & & 0.197 & 0.084 & 5.46 & 0.019 \\
\hline & Weebill & & & & & 0.139 & 0.070 & 3.93 & 0.047 \\
\hline
\end{tabular}



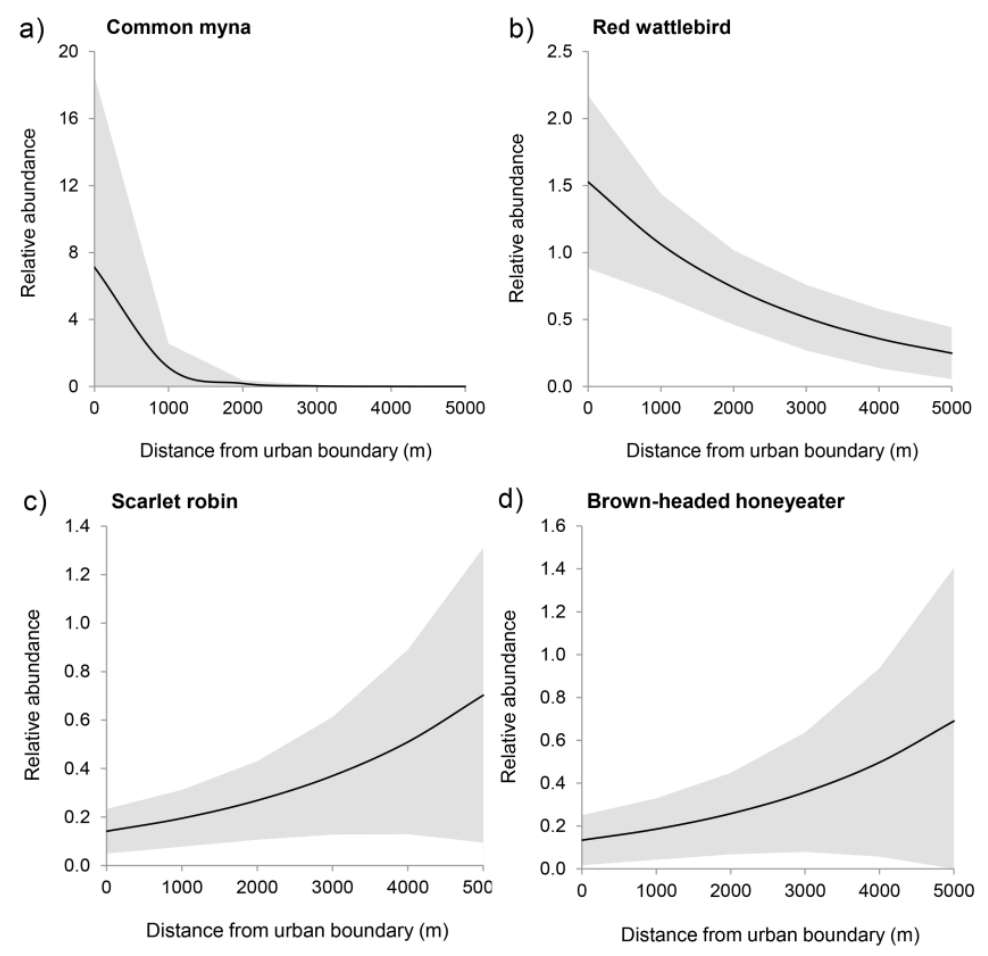

Figure 4. Examples of two species responding positively to urban proximity (a-b), and two species responding negatively to urban proximity (c-d). Plots show predicted trends (bold line) with 95\% confidence intervals (shaded grey). All responses are significant at $\alpha=0.05$. Note: $\mathrm{Y}$ axes are scaled to best visualise responses and vary between species.

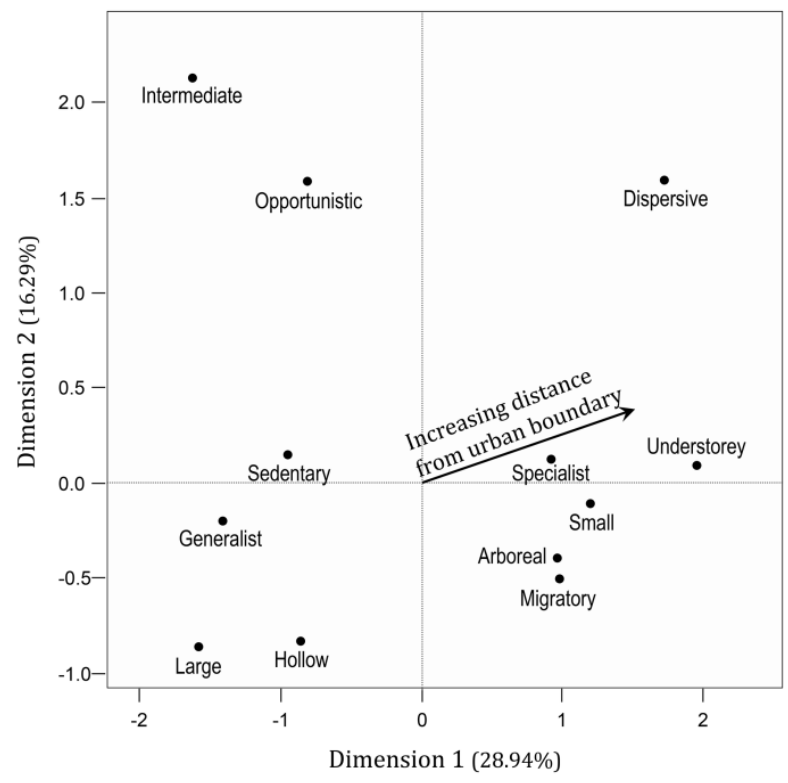

Figure 5. FAMD ordination indicating a clear shift in species trait groups along a gradient of urban proximity (Dimension 1). Traits included in the ordination were: habitat specialisation (Generalist, Specialist), body size (Small, Intermediate, Large), mobility (Sedentary, Migratory, Dispersive) and nesting substrate (Hollow, Arboreal, Understorey, Opportunistic). 


\section{Hypothesis 2: Effects of urban change}

\section{Individual species responses to annual change}

We identified 15 species whose reporting rates or abundances were significantly related to Urban Annual Change (Table 2). Responses to annual change were primarily negative with reporting rates or abundances of 12 species decreasing as rate of change in urban proximity increased (hereafter rapid change intolerant, e.g Figure 6a, Brown Treecreeper). However, three species showed the opposite effect, responding positively to increasing annual changes in urban proximity (hereafter rapid change tolerant, e.g. Figure $6 \mathrm{~b}$, White-plumed Honeyeater). Most species that were influenced by annual change also exhibited a significant relationship with distance (9/15 species), but these associations were not always intuitive. For example, the White-plumed Honeyeater and Rufous Whistler both responded negatively to urban proximity, but positively to increasing annual change. Two species, the Grey Currawong and Varied Sittella, showed negative responses to annual change with no significant response to Urban Distance. Overall, we found no observable effects of annual change on the reporting rates or abundances of most species in the dataset $(n=44)$.

\section{Trait-based responses to annual change}

Dimensions one and two of our FAMD explained $56 \%$ of variability in trait-based responses to annual urban change. However, patterns in the response of trait groups were less clear for change than for distance (Figure 7). This may be due to the small number of species included in the ordination (15 species listed in Table 2). There was no clear association between annual change and species body size. However, we found some evidence to suggest that sites experiencing lower rates of annual change support more generalist, sedentary and hollow-dependent species.

\section{Individual species responses to long-term change}

We identified 15 species whose reporting rates or abundances calculated in the final two years of surveys (2011/2012) were significantly related to Long-term Urban Change (Table 3). Species with positive associations tended to be urban exploiters (Table 3) that typically occupied sites located near to the urban boundary at the start of the observation period, where limited encroachment had taken place over the preceding 12 years. Species with negative associations tended to be urban avoiders (Table 3) that typically occupied sites further from the urban boundary at the start of the observation period, which were sites subjected to higher rates of encroachment over the the preceding 12 years.

We found no strong link between the population trends of species that exhibited positive associations with long-term urban change. These species showed a combination of increasing, stable and declining trends in our study area. However, species negatively associated with long-term urban change showed only stable or declining population trends in our study area. Three urban-avoiding species (the Scarlet Robin, Striated Thornbill and Rufous Whistler) showed both negative association with long-term urban change and a long-term declining population trend. 
Table 2. Relationships between annual incremental change in urban proximity and species (a) reporting rates and (b) relative abundances. Positive estimates indicate higher reporting rates/abundances on sites where the annual rate of urban change is slower. Only species showing a significant response to urban annual change $(\alpha=0.05)$ are listed. Exotic species are denoted by an asterisk $(*)$. Scientific names for species are provided in Appendix S1.

\begin{tabular}{|c|c|c|c|c|c|c|c|c|c|}
\hline \multirow{2}{*}{ Response } & \multirow{2}{*}{ Species } & \multicolumn{4}{|c|}{ (a) Reporting rate } & \multicolumn{4}{|c|}{ (b) Relative abundance } \\
\hline & & Est. & SE & Wald & $\mathbf{P}$ & Est. & SE & Wald & $\mathbf{P}$ \\
\hline \multirow[t]{3}{*}{ Rapid change tolerant } & Eastern Spinebill & -0.125 & 0.045 & 7.69 & 0.006 & & & & \\
\hline & White-plumed Honeyeater & -0.207 & 0.087 & 5.67 & 0.017 & -0.234 & 0.079 & 8.80 & 0.003 \\
\hline & Rufous Whistler & -0.087 & 0.044 & 3.99 & 0.046 & & & & \\
\hline \multirow[t]{12}{*}{ Rapid change intolerant } & Brown Treecreeper & 0.877 & 0.225 & 15.17 & $<0.001$ & 1.299 & 0.218 & 35.40 & $<0.001$ \\
\hline & Tree Martin & 0.734 & 0.160 & 21.15 & $<0.001$ & & & & \\
\hline & Grey Currawong & 0.313 & 0.109 & 8.26 & 0.004 & & & & \\
\hline & Red-rumped Parrot & & & & & 0.319 & 0.130 & 6.06 & 0.014 \\
\hline & Varied Sittella & 0.338 & 0.116 & 8.50 & 0.004 & & & & \\
\hline & White-naped Honeyeater & & & & & 0.212 & 0.104 & 4.11 & 0.043 \\
\hline & Mistletoebird & 0.156 & 0.057 & 7.45 & 0.006 & 0.119 & 0.053 & 5.04 & 0.025 \\
\hline & Brown-headed Honeyeater & & & & & 0.170 & 0.065 & 6.92 & 0.009 \\
\hline & White-winged Chough & & & & & 0.159 & 0.064 & 6.11 & 0.013 \\
\hline & Common Starling* & 0.247 & 0.103 & 5.78 & 0.016 & & & & \\
\hline & Golden Whistler & 0.187 & 0.085 & 4.84 & 0.028 & 0.173 & 0.084 & 4.26 & 0.039 \\
\hline & Galah & & & & & 0.128 & 0.059 & 4.75 & 0.029 \\
\hline
\end{tabular}



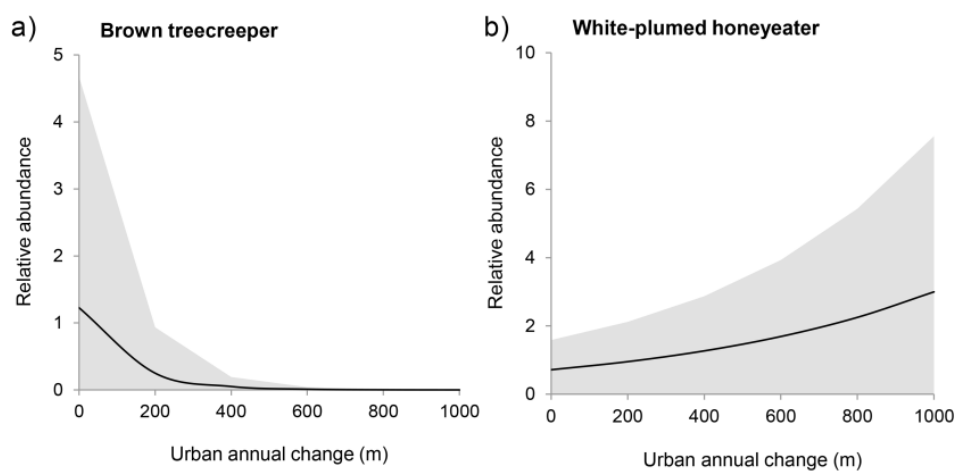

Figure 6. Examples of two species responding to increasing urban annual change: one positively (e) and one negatively (f). Plots show predicted trends (bold line) with 95\% confidence intervals (shaded grey). All responses are significant at $\alpha=0.05$. Note: Y axes are scaled to best visualise responses and vary between species.

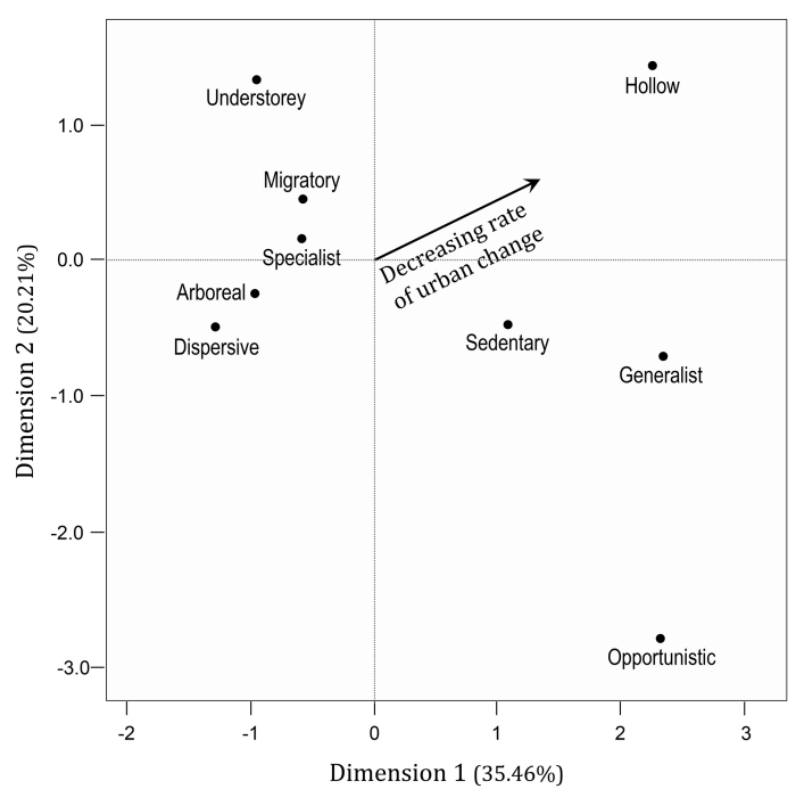

Figure 7. FAMD ordination showing limited similarity among species trait groups in response to annual change in urban proximity. Traits included in the ordination were: habitat specialisation (Generalist, Specialist), mobility (Sedentary, Migratory, Dispersive) and nesting substrate (Hollow, Arboreal, Understorey, Opportunistic). 



\section{DISCUSSION}

In this paper, we tested two hypotheses of how woodland bird occurrence might be directly influenced by urban fringe development: (1) via the spatial proximity of urban development and (2) via the rate of change in urban proximity. Based on data from a spatially replicated long-term monitoring project, our study shows that the occurrence of approximately half of the region's avifauna is strongly linked to the proximity of their habitat to urban fringe development, but that the impact of urban fringe development on the occurrence of some species is also temporally dependent. These findings, and their implications for conservation management, are discussed below.

\section{Hypothesis 1: Proximity of urban fringe development}

More than half of our study species showed a clear relationship to urban proximity and, within that group of species, positive and negative responses were almost evenly split. Most urban exploiters identified in this study were species that we would expect, and possessed traits that we would expect, based, on the literature (e.g. Luck \& Smallbone, 2010). The tendency for urban exploiters to be woodland generalists is supported by Bonier et al. (2007) who demonstrated that, globally, urban birds have broad environmental tolerances (as indicated by their larger geographical ranges). There is also substantial support for urban exploiters being larger, exotic and sedentary (McKinney, 2002; Garden et al., 2006; Kark et al., 2007; Croci et al., 2008; Luck \& Smallbone, 2010), as found in this study.

Conversely, our finding that urban exploiters were more likely to be hollow-dependent is interesting, and both supported (Kluza et al., 2000; Miller et al., 2003; Chace \& Walsh, 2006) and contradicted (Sandström et al., 2006; Pidgeon et al., 2007) by the literature. Within Australia, the relationship between hollow-nesters and urbanisation is suggested to be negative due to the mechanisms underlying hollow development and the removal of senescing trees from urban landscapes (Shanahan et al., 2013; Le Roux et al. 2014). Indeed, within our study area, previous research indicates that hollow-nesters decline in occurrence from the suburb-reserve interface to the suburb core (Ikin et al., 2014). However, our results suggest that this relationship is one of more complex urban adaptation (sensu Johnston, 2001), where hollow-nesters are attracted to novel resources within the urban boundary, but critically rely on natural resources (i.e. remnant trees) that are more abundant outside the urban boundary (McKinney, 2002; Blewett \& Marzluff 2005). This would explain why hollow-nesters appear to favour urban fringe habitats in our study, declining as distances increase both into the suburbs and away from the urban fringe.

A key outcome of our study was the identification of urban avoiders, because these species may require greater conservation effort as urban centres continue to expand and opportunities for protection through new reserves become limited (Mcdonald et al., 2009). Perhaps unsurprisingly, a number of urban avoiders identified in this study are woodland-dependent species that have shown declines in the study area (Table 3) or in various parts of south-eastern Australia over the last decade (e.g. Dusky Woodswallow, Sacred Kingfisher, Scarlet Robin, Striated Thornbill, Superb Fairy-wren, Tree Martin; Barrett et al., 2007; Szabo et al., 2011). Specialised habitat requirements, and a reliance on natural resources, are common traits among urban avoiding species (McKinney, 2002; Møller, 2009; Luck \& Smallbone, 2010).

In addition to their habitat specialisation, urban avoiders were found in this study to be smallbodied, migratory or dispersive, and dependent on mid and upper canopy structures for nesting. This is consistent with the literature (Lim \& Sodhi, 2004: Garden et al., 2006; Kark et al., 2007). It is documented that mid and upper canopy structures are reduced in urban environments (Chace \& Walsh, 2006; Le Roux et al. 2014), but the avoidance of urban areas by migrants is also suggested to be linked to nesting requirements (Kark et al., 2007). Specifically, sedentary species may occupy the limited number of nest sites during the absence of migratory species, thus gaining a competitive advantage in urban systems (Kark et al., 2007). This also supports arguments that nesting requirements are a strong determinant of urban tolerance for birds (Lim \& Sodhi, 2004; Marzluff \& Neatherlin 2006). 
Another important inter-specific interaction to consider involves the presence of the Noisy Miner (Manorina melanocephala). The Noisy Miner is an abundant species commonly found in urban areas, but was identified as an urban avoider because its reporting rate significantly increased with distance from the boundary. Given the documented impact of this hyper-aggressive species on woodland bird communities (Montague-Drake et al., 2011) and its strong increasing trend in our study area (Rayner et al. unpublished data), additional work is needed to examine the relative effects of Noisy Miner occurrence and urban fringe development on sites where other avoider species co-occur. In the present study, the occurrence of the Noisy Miner is unlikely to have biased our definition of urban avoiders because this species shows strong site fidelity and was absent from, or rare in (present in $<10$ surveys over 12 years) the majority of our study sites $(n=72 / 92)$.

\section{Hypothesis 2: Change in urban fringe development}

Species responses to urban fringe development are not driven by proximity alone. For some species, the rate of change in urban proximity also contributes to observed patterns of occurrence. For example, the Common Starling (exotic and declining; Barrett et al., 2007; Rayner et al. unpublished data) and Mistletoebird (declining; Szabo et al., 2011; Rayner et al. unpublished data) both responded positively to urban proximity, but were negatively impacted by increasing rates of urban change. That is, the greater the annual change in urban proximity, the less likely we were to observe these species on a site. Other species, such as the Grey Currawong and Varied Sittella did not exhibit significant relationships with urban distance at all, but also showed supressed reporting rates with rapid changes at the urban fringe. Both of these species are declining more broadly (Barrett et al., 2007). Of greatest concern are species that exhibited both a negative response to urban proximity and change, such as the Brown Treecreeper (listed as near threatened; EPBC, 1999), Tree Martin (declining; Barrett et al., 1994; Paton et al., 2004; Szabo et al., 2011) and Golden Whistler. These examples demonstrate that urban fringe development is having a detrimental impact on those bird species which are often of conservation concern, but in a way that is not captured by static distance metrics alone.

Common traits were generally lacking among species responding to urban change. However, our results indicate that generalist, sedentary and hollow-dependent species, which are typically favoured by urban environments (Figure 5), are negatively affected by large annual shifts in proximity. If the response of these trait groups to urban fringe development is driven primarily by resource availability (McKinney, 2002), it is possible that the human-subsidised resources favouring these species groups are not available in the initial phase of urban construction (i.e. within one year). This supports arguments that species responses to urban fringe development are likely to change through time (Scott, 1993) and that the age of a suburb is a strong determinant in how communities respond to urbanisation (Møller et al., 2012). Indeed, we found little congruence between the responses of species to rapid, short-term changes in urban fringe development and the delayed, longer-term effects of an established urban suburb. Pearce-Higgins et al. (2012) found a similar pattern of response for birds inhabiting areas adjacent to wind farms in the United Kingdom, where population declines were linked to immediate construction disturbance rather than subsequent operation. Unfortunately, we found no comparative studies examining this effect in urban fringe environments elsewhere around the world.

When relating species population trends to the extent of urban change in the preceding 12 years, we found little support for a linear association. That is, species in areas subject to minimal urban encroachment showed variable long-term trend responses, including population increases and declines. However, areas of most extensive change in urban fringe development were more often associated with species exhibiting stable or declining trend patterns, and these species were more likely to be urban avoiders. This finding suggests that long-term changes in urban fringe development may be influencing woodland bird persistence, but that its effects could be spatially dependent on other landscape factors.

One such factor influencing species responses to urban fringe development may be the spatial distribution of protected areas. In our study system, protected areas have been established around most of the sites that were subject to the highest rate of urban change over the last decade (Rayner $e t$ 
al., 2014). Direct conservation action within reserves that target the protection of woodland avifauna (such as predator removal and the addition of coarse woody debris; Manning et al., 2011; Shorthouse et al., 2012) may have influenced our results on long-term responses to urban change by reducing the detectable impact of rapid, large-scale urban encroachment. While this result has the potential to be an encouraging conservation outcome, the role of protected areas for abating the impacts of urban fringe development remain inconclusive without further replication of areas subject to high urban change in the absence of formal protection.

\section{Management implications}

Defining conservation objectives in urban fringe environments remains an important challenge for conservation biology (Miller \& Hobbs, 2002; Battisti \& Gippoliti, 2004). There is an urgent need for long-term monitoring data to assist the management of species-urban interactions (Chace \& Walsh, 2006). Our study is one of the first to track species responses to urban fringe development through time using empirical data from permanent field monitoring sites. Temporal replication in our surveys lends additional rigour to our assessment of species urban tolerance as significant relationships are based on a consistent response to urban proximity through time.

However, this investigation shows that the examination of proximity alone will not reveal all that we need to know about the impact of urban fringe development on those species occupying fringe habitats. We have discovered that several species respond to the rate of change in development at the urban fringe. Given that these species are frequently of conservation concern regionally and nationally, we argue that testing the response of species to urban change provides critical insight to those taxa that are particularly vulnerable to urban-related disturbance. We provide examples of where our results might be regionally specific and encourage careful consideration of ecological context when examining the effects urban fringe development elsewhere (Luck \& Smallbone, 2010).

The adverse effect of urban fringe development on the reporting rates and abundances of vulnerable species warrants careful attention in terms of conservation management and planning. At a minimum, our findings suggest that vegetation (specifically mid- and upper-canopy structures) should be retained wherever possible in urban environments, particularly during the construction phase of development. In addition, future urban expansion toward important fringe habitats (e.g. endangered ecological communities or areas supporting threatened species) will need to be planned strategically through space and time. Spatially, we detected urban proximity effects on species frequently beyond 3 $\mathrm{km}$ (and up to $5 \mathrm{~km}$ ) from the urban boundary. Decision makers will need to consider this distance when acquiring land for future urban fringe development in areas of high conservation value. Planners will need to do their best to minimise construction-related disturbance, particularly on large development blocks. Ideally, the spatial scale of suburbs also would be considered prior to establishment. Avoiding blocks of development that result in large advances toward sensitive habitats would be preferable so that species sensitive to urban fringe development can benefit from smaller incremental changes in urban encroachment. 


\section{ACKNOWLEDGMENTS}

This research received funding support from Conservation Planning and Research, Environment and Sustainable Development Directorate ACT Government and the Fenner School of Environment and Society. DBL, PG and KI were supported by the National Environmental Research Program. ADM was supported by an ARC Future Fellowship (FT100100358). We thank the Canberra Ornithologists Group for providing bird records.We thank C. Sato, J. Wood, P. Barton, V. Radeloff, D. Shanahan and one anonymous reviewer for improvements to the manuscript.

\section{REFERENCES}

ABS (2013) Ausralia Bureau of Statistics. Regional Population Growth, Australia, 2012-13 Australian Capital Territory. Available at: http://www.abs.gov.au/ausstats/abs@.nsf/Products/3218.0 201213 Main+Features Australian+Capital+Territory?OpenDocument (accessed 28 May 2014)

ACT (2011) Australian Capital Territory Government. ACT State of the Environment Report 2011. Available at: http://www.envcomm.act.gov.au/actsoe2011/index.html (accessed 28 May 2014)

Aronson, M.F., La Sorte, F.A., Nilon, C.H., Katti, M., Goddard, M.A., Lepczyk, C.A., Warren, P.S., Williams, N.S., Cilliers, S. \& Clarkson, B. (2014) A global analysis of the impacts of urbanization on bird and plant diversity reveals key anthropogenic drivers. Proceedings of the Royal Society B: Biological Sciences, 281, 20133330.

Barrett, G., Ford, H.A. \& Recher, H. (1994) Conservation of woodland birds in a fragmented rural landscape. Pacific Conservation Biology, 1, 245.

Barrett, G., Silcocks, A., Cunningham, R., Oliver, D., Weston, M. \& Baker, J. (2007) Comparison of atlas data to determine the conservation status of bird species in New South Wales, with an emphasis on woodland-dependent species. Australian Zoologist, 34, 37-77.

Battisti, C. \& Gippoliti, S. (2004) Conservation in the urban-countryside interface: a cautionary note from Italy. Conservation Biology, 18, 581-583.

Bekessy, S.A., White, M., Gordon, A., Moilanen, A., McCarthy, M.A. \& Wintle, B.A. (2012) Transparent planning for biodiversity and development in the urban fringe. Landscape and Urban Planning, 108, 140-149.

Blair, R.B. (1996) Land use and avian species diversity along an urban gradient. Ecological applications, 6, 506-519.

Blewett, C. M. \& Marzluff, J. M. (2005) Effects of urban sprawl on snags and the abundance and productivity of cavity-nesting birds. The Condor, 107, 678-693.

Bonier, F., Martin, P.R. \& Wingfield, J.C. (2007) Urban birds have broader environmental tolerance. Biology letters, 3, 670-673.

Bounds, J., Taws, N. \& Cunningham, R. (2010) A statistical analysis of trends in occupancy rates of woodland birds in the ACT, December 1998 to December 2008: the ten-year data analysis. Canberra Bird Notes, 35, 158-192.

Brearley, G., Bradley, A., Bell, S. \& McAlpine, C. (2010) Influence of contrasting urban edges on the abundance of arboreal mammals: A study of squirrel gliders (Petaurus norfolcensis) in southeast Queensland, Australia. Biological conservation, 143, 60-71.

Burton, N.H., Rehfisch, M.M. \& Clark, N.A. (2002) Impacts of disturbance from construction work on the densities and feeding behavior of waterbirds using the intertidal mudflats of Cardiff Bay, UK. Environmental Management, 30, 0865-0871.

Chace, J.F. \& Walsh, J.J. (2006) Urban effects on native avifauna: a review. Landscape and urban planning, 74, 46-69.

Chamberlain, D., Cannon, A., Toms, M., Leech, D., Hatchwell, B. \& Gaston, K. (2009) Avian productivity in urban landscapes: a review and meta-analysis. Ibis, 151, 1-18.

Cincotta, R.P., Wisnewski, J. \& Engelman, R. (2000) Human population in the biodiversity hotspots. Nature, 404, 990-992. 
Croci, S., Butet, A. \& Clergeau, P. (2008) Does Urbanization Filter Birds on the Basis of Their Biological Traits. The Condor, 110, 223-240.

Crossman, N., Bryan, B., Ostendorf, B. \& Collins, S. (2007) Systematic landscape restoration in the rural-urban fringe: meeting conservation planning and policy goals. Biodiversity and Conservation, 16, 3781-3802.

Dallimer, M., Rouquette, J.R., Skinner, A.M., Armsworth, P.R., Maltby, L.M., Warren, P.H. \& Gaston, K.J. (2012) Contrasting patterns in species richness of birds, butterflies and plants along riparian corridors in an urban landscape. Diversity and Distributions, 18, 742-753.

EPBC (1999) Environment Protection and Biodiversity Conservation Act 1999. Available at: http://www.environment.gov.au/cgi-bin/sprat/public/publicthreatenedlist.pl?wanted=fauna (accessed 28 May 2014).

Fisher, T. (2003) Differentiation of growth processes in the peri-urban region: an Australian case study. Urban Studies, 40, 551-565.

Foley, J.A., DeFries, R., Asner, G.P., Barford, C., Bonan, G., Carpenter, S.R., Chapin, F.S., Coe, M.T., Daily, G.C. \& Gibbs, H.K. (2005) Global consequences of land use. science, 309, 570-574.

Forys, E.A. \& Allen, C.R. (2005) The impacts of sprawl on biodiversity: the ant fauna of the lower Florida Keys.

Garden, J., Mcalpine, C., Peterson, A., Jones, D. \& Possingham, H. (2006) Review of the ecology of Australian urban fauna: a focus on spatially explicit processes. Austral Ecology, 31, 126-148.

Grimm, N.B., Faeth, S.H., Golubiewski, N.E., Redman, C.L., Wu, J., Bai, X. \& Briggs, J.M. (2008) Global change and the ecology of cities. Science, 319, 756-760.

Güneralp, B. \& Seto, K. (2013) Futures of global urban expansion: Uncertainties and implications for biodiversity conservation. Environmental Research Letters, 8, 014025.

Husson, F., Josse, J., Le, S. \& Mazet, J. (2014). FactoMineR: Multivariate Exploratory Data Analysis and Data Mining with R. R package version 1.26. http://CRAN.Rproject.org/package=FactoMineR

Ikin, K., Knight, E., Lindenmayer, D.B., Fischer, J. \& Manning, A.D. (2013) The influence of native versus exotic streetscape vegetation on the spatial distribution of birds in suburbs and reserves. Diversity and Distributions, 19, 294-306.

Ikin, K., Barton, P., Knight, E., Lindenmayer, D., Fischer, J. \& Manning, A. (2014) Bird community responses to the edge between suburbs and reserves. Oecologia, 174, 545-557.

Johnston, R.F. (2001) Synanthropic birds of north America. Avian ecology and conservation in an urbanizing world, pp. 49-67. Springer.

Kark, S., Iwaniuk, A., Schalimtzek, A. \& Banker, E. (2007) Living in the city: can anyone become an 'urban exploiter'? Journal of Biogeography, 34, 638-651.

Kluza, D.A., Griffin, C.R. \& Degraaf, R.M. (2000) Housing developments in rural New England: effects on forest birds. Animal Conservation, 3, 15-26.

Le Roux, D. S., Ikin, K., Lindenmayer, D. B., Blanchard, W., Manning, A. D. \& Gibbons, P. (2014) Reduced availability of habitat structures in urban landscapes: Implications for policy and practice. Landscape and Urban Planning, 125, 57-64.

Lim, H.C. \& Sodhi, N.S. (2004) Responses of avian guilds to urbanisation in a tropical city. Landscape and Urban Planning, 66, 199-215.

Lindenmayer, D., Bennett, A. \& Hobbs, R. (2010) Temperate Woodland Conservation and Management. CSIRO Publishing, Melbourne.

Luck, G.W. (2007) The relationships between net primary productivity, human population density and species conservation. Journal of Biogeography, 34, 201-212.

Luck, G.W. \& Smallbone, L.T. (2010) Species diversity and urbanisation: patterns, drivers and implications. Urban ecology (ed. by K. J. Gaston), pp. 88-119. Cambridge University Press, UK.

MacLeod, N., McIntyre, S., McIvor, J. \& Heard, K. (2002) Principles for property planning. Managing and conserving grassy woodlands, 25-40.

Manning, A., Wood, J., Cunningham, R., McIntyre, S., Shorthouse, D., Gordon, I. \& Lindenmayer, D. (2011) Integrating research and restoration: the establishment of a long-term woodland experiment in south-eastern Australia. Australian Zoologist, 35, 633-648. 
Marzluff, J. M. \& Ewing, K. (2001) Restoration of fragmented landscapes for the conservation of birds: a general framework and specific recommendations for urbanizing landscapes. Restoration Ecology, 9, 280-292.

Marzluff, J. M. \& Neatherlin, E. (2006) Corvid response to human settlements and campgrounds: causes, consequences, and challenges for conservation. Biological conservation, 130, 301-314.

Marzluff, J. M., Bowman, R. \& Donnelly, R. (2001) A historical perspective on urban bird research: trends, terms, and approaches. In Avian ecology and conservation in an urbanizing world (pp. 117). Springer US.

Mcdonald, R.I., Forman, R.T., Kareiva, P., Neugarten, R., Salzer, D. \& Fisher, J. (2009) Urban effects, distance, and protected areas in an urbanizing world. Landscape and Urban Planning, 93, 63-75.

McKinney, M.L. (2002) Urbanization, Biodiversity, and Conservation. BioScience, 52, 883-890.

McKinney, M.L. (2006) Urbanization as a major cause of biotic homogenization. Biological conservation, 127, 247-260.

Miller, J.R. \& Hobbs, R.J. (2002) Conservation where people live and work. Conservation Biology, 16, 330-337.

Miller, J.R., Wiens, J.A., Hobbs, N.T. \& Theobald, D.M. (2003) Effects of human settlement on bird communities in lowland riparian areas of colorado (USA). Ecological Applications, 13, 10411059.

Møller, A.P. (2009) Successful city dwellers: a comparative study of the ecological characteristics of urban birds in the Western Palearctic. Oecologia, 159, 849-858.

Møller, A.P., Diaz, M., Flensted-Jensen, E., Grim, T., Ibáñez-Álamo, J.D., Jokimäki, J., Mänd, R., Markó, G. \& Tryjanowski, P. (2012) High urban population density of birds reflects their timing of urbanization. Oecologia, 170, 867-875.

Montague-Drake, R.M., Lindenmayer, D.B., Cunningham, R.B. \& Stein, J.A. (2011) A reverse keystone species affects the landscape distribution of woodland avifauna: a case study using the Noisy Miner (Manorina melanocephala) and other Australian birds. Landscape ecology, 26, 1383-1394.

Paton, D.C., Rogers, D.J. \& Harris, W. (2004) Birdscaping the environment: restoring the woodland systems of the Mt Lofty region, South Australia. Conservation of Australia's Forest Fauna Second edition. (ed. by D. Lunney). Royal Zoological Society of New South Wales, Sydney.

Pautasso, M. (2007) Scale dependence of the correlation between human population presence and vertebrate and plant species richness. Ecology Letters, 10, 16-24.

Pearce-Higgins, J.W., Stephen, L., Douse, A. \& Langston, R.H.W. (2012) Greater impacts of wind farms on bird populations during construction than subsequent operation: results of a multi-site and multi-species analysis. Journal of Applied Ecology, 49, 386-394.

Pidgeon, A.M., Radeloff, V.C., Flather, C.H., Lepczyk, C.A., Clayton, M.K., Hawbaker, T.J. \& Hammer, R.B. (2007) Associations of forest bird species richness with housing and landscape patterns across the USA. Ecological Applications, 17, 1989-2010.

Prober, S.M. \& Smith, F.P. (2009) Enhancing biodiversity persistence in intensively used agricultural landscapes: a synthesis of 30 years of research in the Western Australian wheatbelt. Agriculture, ecosystems \& environment, 132, 173-191.

Radeloff, V.C., Hammer, R.B., Stewart, S.I., Fried, J.S., Holcomb, S.S. \& McKeefry, J.F. (2005) The wildland-urban interface in the United States. Ecological applications, 15, 799-805.

Radeloff, V.C., Stewart, S.I., Hawbaker, T.J., Gimmi, U., Pidgeon, A.M., Flather, C.H., Hammer, R.B. \& Helmers, D.P. (2010) Housing growth in and near United States protected areas limits their conservation value. Proceedings of the National Academy of Sciences, 107, 940-945.

Rayner, L., Lindenmayer, D.B., Wood, J.T., Gibbons, P. \& Manning, A.D. (2014) Are protected areas maintaining bird diversity? Ecography, 37, 43-53.

Reijnen, R. \& Foppen, R. (2006) Impact of road traffic on breeding bird populations. The ecology of transportation: managing mobility for the environment, pp. 255-274. Springer.

Robinson, L., Newell, J.P. \& Marzluff, J.M. (2005) Twenty-five years of sprawl in the Seattle region: growth management responses and implications for conservation. Landscape and Urban planning, 71, 51-72. 
Sandström, U., Angelstam, P. \& Mikusiński, G. (2006) Ecological diversity of birds in relation to the structure of urban green space. Landscape and Urban Planning, 77, 39-53.

Scott, T.A. (1993) Initial effects of housing construction on woodland birds along the wildland urban interface. Interface between Ecology and Land Development in California. (ed. by J. E. Keeley). Southern California Academy of Sciences, Los Angeles, USA.

Seto, K.C., Güneralp, B. \& Hutyra, L.R. (2012) Global forecasts of urban expansion to 2030 and direct impacts on biodiversity and carbon pools. Proceedings of the National Academy of Sciences, 109, 16083-16088.

Shanahan, D.F., Strohbach, M.W., Warren, P.S. \& Fuller, R.A. (2013) The challenges of urban living. Avian Urban Ecology: Behavioural and Physiological Adaptations (ed. by D. Gil and H. Brumm), pp. 3-20. Oxford University Press, UK.

Shorthouse, D.J., Iglesias, D., Jeffress, S., Lane, S., Mills, P., Woodbridge, G., McIntyre, S. \& Manning, A.D. (2012) The 'making of' the Mulligans Flat-Goorooyarroo experimental restoration project. Ecological Management \& Restoration, 13, 112-125.

Sol, D., González-Lagos, C., Moreira, D., Maspons, J. \& Lapiedra, O. (2014) Urbanisation tolerance and the loss of avian diversity. Ecology Letters, DOI: 10.1111/ele.12297

Sorace, A. \& Gustin, M. (2010) Bird species of conservation concern along urban gradients in Italy. Biodiversity and conservation, 19, 205-221.

Szabo, J.K., Vesk, P.A., Baxter, P.W. \& Possingham, H.P. (2011) Paying the extinction debt: woodland birds in the Mount Lofty Ranges, South Australia. Emu, 111, 59-70.

Turner, W.R., Nakamura, T. \& Dinetti, M. (2004) Global urbanization and the separation of humans from nature. Bioscience, 54, 585-590.

Wania, A., Kühn, I. \& Klotz, S. (2006) Plant richness patterns in agricultural and urban landscapes in Central Germany-spatial gradients of species richness. Landscape and Urban Planning, 75, 97 110 . 
Appendix S1. List of species with assigned functional traits. Nomenclature for species names taken from Christidis \& Boles 2008. Habitat guilds taken from Reid \& Cunningham 2008. Mobility derived from Reid 1999 and Lindenmayer et al. 2011. Body size and nesting traits derived from Ikin et al. 2012 and Lindenmayer et al. 2011. Full references are provided below.

\begin{tabular}{|c|c|c|c|c|c|}
\hline Common name & Scientific name & Habitat & Mobility & Size & Nesting \\
\hline Australian King-Parrot & Alisterus scapularis & WG & Sedentary & Large & Hollow \\
\hline Australian Magpie & Gymnorhina tibicen & WG & Sedentary & Large & Arboreal \\
\hline Australian Raven & Corvus coronoides & WG & Sedentary & Large & Arboreal \\
\hline Black-faced Cuckoo-shrike & Coracina novaeHollowlandiae & WS & Migratory & Large & Arboreal \\
\hline Brown Thornbill & Acanthiza pusilla & WS & Sedentary & Small & Understy \\
\hline Brown Treecreeper & Climacteris picumnus & WS & Sedentary & Small & Hollow \\
\hline Brown-headed Homeyeater & Melithreptus brevirostris & WS & Sedentary & Small & Arboreal \\
\hline Buff-rumped Thornbill & Acanthiza reguloides & WS & Sedentary & Small & Opportn \\
\hline Common Bronzewing & Phaps chalcoptera & WS & Migratory & Large & Opportn \\
\hline Common Myna & Acridotheres tristis & WG & Sedentary & Large & Hollow \\
\hline Common Starling & Sturnus vulgaris & WG & Sedentary & Interm & Opportn \\
\hline Crested Pigeon & Ocyphaps lophotes & WG & Sedentary & Large & Opportn \\
\hline Crimson Rosella & Platycercus elegans & WG & Sedentary & Large & Hollow \\
\hline Dusky Woodswallow & Artamus cyanopterus & WS & Dispersive & Small & Opportn \\
\hline Eastern Rosella & Platycercus eximius & WS & Sedentary & Large & Hollow \\
\hline Eastern Spinebill & Acanthorhynchus tenuirostris & WS & Migratory & Small & Arboreal \\
\hline Galah & Cacatua roseicapilla & WG & Sedentary & Large & Hollow \\
\hline Gang-gang Cockatoo & Callocephalon fimbriatum & WS & Migratory & Large & Hollow \\
\hline Golden Whistler & Pachycephala pectoralis & WS & Migratory & Small & Understy \\
\hline Grey Butcherbird & Cracticus torquatus & WS & Sedentary & Interm & Opportn \\
\hline Grey Currawong & Strepera versicolor & WS & Sedentary & Large & Arboreal \\
\hline Grey Fantail & Rhipidura fuliginosa & WS & Migratory & Small & Arboreal \\
\hline Grey Shrike-thrush & Colluricincla harmonica & WS & Sedentary & Interm & Opportn \\
\hline Laughing Kookaburra & Dacelo novaeguineae & WS & Sedentary & Large & Hollow \\
\hline Leaden Flycatcher & Myiagra rubecula & WS & Migratory & Small & Arboreal \\
\hline Magpie-lark & Grallina cyanoleuca & WG & Sedentary & Interm & Arboreal \\
\hline Mistletoebird & Dicaeum hirundinaceum & WS & Dispersive & Small & Arboreal \\
\hline Noisy Friarbird & Philemon corniculatus & WS & Migratory & Large & Arboreal \\
\hline Noisy Miner & Manorina melanocephala & WG & Sedentary & Interm & Opportn \\
\hline Olive-backed Oriole & Oriolus sagittatus & WS & Migratory & Interm & Arboreal \\
\hline Pied Currawong & Strepera graculina & WG & Migratory & Large & Arboreal \\
\hline Red Wattlebird & Anthochaera carunculata & WG & Migratory & Large & Arboreal \\
\hline Red-rumped Parrot & Psephotus haematonotus & WS & Sedentary & Interm & Hollow \\
\hline Rufous Whistler & Pachycephala rufiventris & WS & Migratory & Small & Arboreal \\
\hline Sacred Kingfisher & Todiramphus sanctus & WS & Migratory & Small & Hollow \\
\hline Scarlet Robin & Petroica multicolor & WS & Sedentary & Small & Arboreal \\
\hline Silvereye & Zosterops lateralis & WS & Migratory & Small & Arboreal \\
\hline Speckled Warbler & Chthonicola sagittata & WS & Sedentary & Small & Understy \\
\hline Spotted Pardalote & Pardalotus punctatus & WS & Sedentary & Small & Hollow \\
\hline Striated Pardalote & Pardalotus striatus & WS & Migratory & Small & Hollow \\
\hline Striated Thornbill & Acanthiza lineata & WS & Sedentary & Small & Arboreal \\
\hline Sulphur-crested Cockatoo & Cacatua galerita & WG & Migratory & Large & Hollow \\
\hline Superb Fairy-wren & Malurus cyaneus & WS & Sedentary & Small & Understy \\
\hline Tree Martin & Hirundo nigricans & WG & Migratory & Small & Hollow \\
\hline Varied Sitella & Daphoenositta chrysoptera & WS & Sedentary & Small & Arboreal \\
\hline
\end{tabular}




\begin{tabular}{llllll} 
Weebill & Smicornis brevirostris & WS & Sedentary & Small & Arboreal \\
Welcome Swallow & Hirundo neoxena & WG & Migratory & Small & Opportn \\
Western Gerygone & Gerygone fusca & WS & Migratory & Small & Arboreal \\
White-eared Honeyeater & Lichenostomus leucotis & WS & Sedentary & Small & Understy \\
White-naped Honeyeater & Melithreptus lunatus & WS & Migratory & Small & Arboreal \\
White-plumed Honeyeater & Lichenostomus pencillatus & WS & Sedentary & Small & Arboreal \\
White-throated Gerygone & Gerygone olivacea & WS & Migratory & Small & Arboreal \\
White-throated Treecreeper & Cormobates leucophaeus & WS & Sedentary & Small & Hollow \\
White-winged Chough & Corcorax melanorhamphos & WS & Sedentary & Large & Arboreal \\
Willie Wagtail & Rhipidura leucophrys & WG & Sedentary & Small & Arboreal \\
Yellow-faced Honeyeater & Lichenostomus chrysops & WS & Dispersive & Small & Understy \\
Yellow-rumped Thornbill & Acanthiza chrysorrhoa & WG & Sedentary & Small & Arboreal \\
\hline
\end{tabular}

Habitat abbreviations: WG=woodland generalist, WS=woodland specialist; Size abbreviations: Interm=intermediate;

Nesting abbreviations: Understy=understorey, Opportn=opportunistic.

Christidis, L. \& Boles, W. (2008) Systematics and taxonomy of Australian birds. Collingwood: CSIRO Publishing

Ikin, K., Knight, E., Lindenmayer, D. B., Fischer, J. \& Manning, A. D. (2012) Linking bird species traits to vegetation characteristics in a future urban development zone: implications for urban planning. Urban Ecosystems, 15, 961-977.

Lindenmayer, D.B. \& Cunningham, R.B. (2011) Longitudinal patterns in bird reporting rates in a threatened ecosystem: Is change regionally consistent? Biological Conservation, 144, 430-440.

Reid, J. R. W. (1999) Threatened and declining birds in the New South Wales sheep-wheat belt: I. Diagnosis, characteristics and management. Canberra: CSIRO Wildlife and Ecology.

Reid, J. \& Cunningham, R.B. (2008). Statistical Analysis of the First Six Years of Bird Surveys for the Cowra Woodland Birds Program: Trends and Implications for Woodland Bird Conservation in the Cowra Shire, NSW. Unpublished Report to Lachlan Catchment Management Authority, Birds Australia and the Fenner School of Environment and Society, ANU, Canberra. 